\title{
Determination of cadmium at ultratrace levels in environmental water samples by means of total reflection X-ray spectrometry after dispersive liquid-liquid microextraction
}

\begin{abstract}
Eva Marguí, ${ }^{* a}$ Ignasi Queralt ${ }^{\mathrm{b}}$ and Manuela Hidalgo ${ }^{\mathrm{a}}$
Until now, the determination of Cd at trace levels in aqueous samples by TXRF has been restricted. When Mo-target X-ray tubes are used, low sensitivity and interferences with Cd L-lines used for quantification prevent trace analysis. Alternatively, when $\mathrm{W}$-target $\mathrm{X}$-ray tubes are used $\mathrm{Cd}$ excitation is limited. For this reason, a sample pretreatment is usually necessary to extract, isolate and concentrate Cd prior to TXRF analysis. In the present contribution, the feasibility of a dispersive liquid-liquid microextraction approach (DLLME) combined with TXRF for ultratrace Cd determination in different types of environmental waters is shown. Parameters affecting the extraction procedure and TXRF measurement conditions have been carefully evaluated to ensure the highest sensitivity for $\mathrm{Cd}$ determination. Using the best analytical conditions, it was found that the minimum cadmium content that could be detected in an aqueous solution was $0.04 \mu \mathrm{g} \mathrm{L}^{-1}$. This value is more than two orders of magnitude lower compared with the direct TXRF analysis of $\mathrm{Cd}$ in aqueous samples. The precision of the methodology was evaluated in terms of relative standard deviation (RSD) of six replicate analyses of a standard solution containing 3 $\mu \mathrm{g} \mathrm{L}^{-1}$. The precision of the method was determined to be approximately $5 \%$ RSD. In order to test the suitability of the method when dealing with complex matrices as well as the influence of interfering ions, the determination of $\mathrm{Cd}$ in spiked water samples (sea water, estuarine water and river water) at the levels of $1 \mu \mathrm{g} \mathrm{L}^{-1}$ and $5 \mu \mathrm{g} \mathrm{L}^{-1}$ was undertaken and $\mathrm{Cd}$ added to the samples was quantitatively determined. Our results give insight into the possibilities of the combination of DLLME and TXRF for ultratrace $\mathrm{Cd}$ determination in different types of environmental waters.
\end{abstract}

Received 6th September 2012

Accepted 21st November 2012

DOI: $10.1039 / \mathrm{c} 2 \mathrm{ja} 30252 \mathrm{~g}$

www.rsc.org/jaas
TXRF system makes use of the fact that, at very low glancing angles of the primary X-ray beam $\left(\sim 0.1^{\circ}\right)$, X-ray photons are almost completely absorbed within thin specimens. Therefore, the high background that would generally occur due to scatter from the sample support is absent, leading to improved detection limits at a $\mu \mathrm{g} \mathrm{L^{-1 }}$ level. ${ }^{6}$ However, the determination of cadmium at this level in aqueous samples by TXRF has been limited due to sensitivity issues and interferences between Cd L-lines and K-lines of the matrix elements (i.e., potassium) when employing Mo-target X-ray tubes. Alternatively, when using $\mathrm{W}$-target X-ray tubes excitation of Cd is limited, especially when using benchtop TXRF systems. Therefore, a sample pre-treatment is usually necessary to extract, isolate and concentrate Cd prior to TXRF analysis.

A large number of sample treatment procedures have been developed to preconcentrate analytes prior to TXRF measurements. Perhaps the most common preconcentration procedures used in combination with TXRF spectrometry are based on complexation and extraction of the analytes by liquid-liquid extraction. A comprehensive overview on that topic can be found in a variety of articles published within the last few
${ }^{a}$ Department of Chemistry, University of Girona, Campus Montilivi, 17071 Girona, Spain.E-mail: eva.margui@udg.edu

${ }^{b}$ Laboratory of X-Ray Analytical Applications, Institute of Earth Sciences "Jaume Almera", CSIC, Solé Sabarís s/n, 08028 Barcelona, Spain 
decades. ${ }^{7}$ In this respect it is important to remark the recent development of faster, simpler, less expensive and more environmentally friendly analytical procedures for metal preconcentration within the framework of the so-called "green analytical chemistry" such as liquid-phase microextraction (LPME). LPME is a solvent-minimized sample pretreatment procedure of the conventional liquid-liquid extraction, in which only a few microlitres of solvent are required to concentrate analytes. ${ }^{8}$ For this reason, LPME is usually combined with atomic techniques which require only a few microliters of liquid to perform a measurement. Electrothermal atomic absorption spectrometry (ETAAS) and electrothermal vaporization inductively coupled plasma mass spectrometry (ETV-ICP-MS) have been previously applied following LPME, and several analytical procedures have been recently published for $\mathrm{Cd}$ determination in water samples using different LPME modes. These include single drop microextraction (SDME), hollow fiber microextraction (HF-LPME) and dispersive liquid-liquid microextraction (DLLME) (see Table 1 for details).

In the present contribution and taking into account the micro-analytical capability of TXRF spectrometry, the feasibility of a DLLME approach combined with TXRF for ultratrace Cd determination in different types of environmental waters is presented. DLLME is based on the cloudy solution formed when an appropriate mixture of an extraction solvent and a disperser solvent is injected into an aqueous sample. The fine droplets of extraction solvent are dispersed through the aqueous sample, allowing its interaction with the analyte. After a rapid extraction procedure, only a few microlitres of organic solvent (containing the extracted metal) are obtained, and thus a microanalytical technique is mandatory to quantify the target metal. In a previous study, we demonstrated the suitability of DLLME to be used in combination with TXRF spectrometry. ${ }^{21}$ The extractant phase required in these procedures should have higher density than water, efficiently extract the target compounds, form a stable cloudy solution and have a low solubility in water.
Usually, chlorine containing organic solvents are good candidates and they are ideal solvents to be measured with TXRF due to their high volatility which facilitates drying of the organic drop on the reflective carrier prior to TXRF analysis. In this study, for the first time to the best of our knowledge, the application of the DLLME procedure for trace Cd determination in aqueous samples using TXRF is proposed. Parameters affecting the extraction procedure and TXRF measurement conditions have been carefully evaluated to ensure optimal sensitivity for $\mathrm{Cd}$ determination at trace levels. Analytical figures of merit such as limits of detection, linearity, precision, and accuracy have been carefully determined and the feasibility of the proposed method has been evaluated by determining the Cd content of spiked environmental waters including seawater, river water and estuarine water.

\section{Experimental}

\subsection{Reagents and solutions}

Stock solutions of $1000 \pm 0.5 \mu \mathrm{g} \mathrm{mL} \mathrm{m}^{-1}$ (Spectroscan, TEKNOLAB $\mathrm{A} / \mathrm{S}$, Norway) of appropriate elements were used to prepare standard solutions and spiked samples. High purity water used for dilution of stock solutions and samples was obtained from a Milli-Q purifier system operated at $18 \mathrm{M} \Omega$ (Millipore Corp., Bedford, MA). The solution of $10 \mathrm{mg} \mathrm{kg}^{-1}$ of Mo used for internal standardization was obtained by appropriate dilution of a Mo stock solution of $1000 \mu \mathrm{g} \mathrm{g}^{-1}$ in an oil matrix (HighPurity standards, USA). This metallorganic standard shows high solubility and could be easily employed as an internal standard in organic matrices.

All organic solvents used in this work (i.e., hexylbenzene, undecane, carbon tetrachloride, chloroform, dihexyl ether and decahydronaphthalene) were of analytical grade quality (SigmaAldrich, Spain). The complexing agent, ammonium pyrrolidine dithiocarbamate (APDC) (>99\%) was also purchased from

Table 1 Comparison of published methods based on LPME procedures for cadmium determination in environmental water samples ${ }^{a}$

\begin{tabular}{|c|c|c|c|c|c|}
\hline SI-SDME & ETAAS & 10 & $30-600$ & Water & 9 \\
\hline SDME & ETAAS & 2 & - & Environmental waters & 11 \\
\hline SDME & ETAAS & 0.7 & $10-1000$ & $\begin{array}{l}\text { Water samples/biological samples } \\
\text { (human hair, pig liver) }\end{array}$ & 12 \\
\hline SFODME & ETAAS & 0.5 & $1-15$ & Water (bottled, tap, sea) & 15 \\
\hline HF-LPME & ETAAS & 0.8 & $56.4-264.8$ & Seawater & 16 \\
\hline HF-LPME & ETV-ICPMS & 4.5 & $20-30000$ & $\begin{array}{l}\text { Environmental waters/biological samples } \\
\text { (leaves, human serum) }\end{array}$ & 17 \\
\hline DLLME & ETAAS & 0.6 & $2-20$ & Water sample & 18 \\
\hline DLLME & ETAAS & 4 & - & Waters (sea, tap, bottle) & 19 \\
\hline
\end{tabular}

${ }^{a}$ SI: sequential injection, SDME: single drop microextraction, ETAAS: electrothermal atomic absorption spectrometry, IL: ionic liquid, HF-LPME: hollow-fiber liquid phase microextraction, ETV-ICPMS: electrothermal vaporization inductively coupled plasma mass spectrometry, FI: flow injection, UA: ultrasound-assisted, SFODME: solidified floating organic drop microextraction. 
Sigma-Aldrich (Spain). The $\mathrm{pH}$ values were adjusted by addition of ammonia and nitric acid solutions (Merck, Spain).

\subsection{Dispersive liquid-liquid microextraction procedure}

A dispersive liquid-liquid microextraction procedure (DLLME) using APDC as the complexing agent was employed to separate and preconcentrate $\mathrm{Cd}$ from environmental water samples prior to TXRF analysis. Briefly, $5 \mathrm{~mL}$ of the aqueous sample or standard solution was placed in a conical glass tube to which $50 \mu \mathrm{L}$ of $0.01 \mathrm{M}$ nitric acid was added to adjust the $\mathrm{pH}(\mathrm{pH} \sim 3)$. Next, a mixture containing $500 \mu \mathrm{L}$ of APDC $0.01 \%$ in methanol (chelating agent + disperser solvent) and $50 \mu \mathrm{L}$ of carbon tetrachloride (extraction solvent) was injected rapidly into the sample solution by means of a micropipette. The mixture was then centrifuged at $4000 \mathrm{rpm}$ for five minutes to achieve phase separation. This resulted in a small volume $(\sim 35 \mu \mathrm{L})$ of organic phase, containing the CdPDC complex, settling at the bottom of the tube. By means of a microsyringe, all the organic phase was transferred into a $0.5 \mathrm{~mL}$ Eppendorf tube which was kept at $4{ }^{\circ} \mathrm{C}$ until TXRF analysis. In Fig. 1 a scheme of the DLLME procedure used is displayed.

\subsection{Sample preparation for TXRF analysis}

In TXRF analysis, the sample carrier plays an important role with regard to the achievement of optimal analytical results. In most cases, the reflective sample carrier is made of quartz or acrylic glass. In this study, quartz glass discs with a diameter of $30 \mathrm{~mm}$ and a thickness of $3 \mathrm{~mm} \pm 0.1 \mathrm{~mm}$ (Bruker-AXS, Germany) were used as sample holders. Firstly, the reflector surface was coated with $10 \mu \mathrm{L}$ of a silicon solution in isopropanol (Serva Electrophoresis GmbH, Germany) and subsequently dried at $100{ }^{\circ} \mathrm{C}$ in order to favor the deposition of the target sample within a small spot on the center of the reflector. Then, an aliquot of $20 \mu \mathrm{L}$ of the preconcentrated water sample or standard solution was transferred onto a pre-heated quartz sample carrier and dried under a laminar flow hood for subsequent TXRF analysis (see Fig. 1).

\subsection{Instrumental and operating conditions}

TXRF analysis of the preconcentrated samples was performed with a benchtop spectrometer "S2 PICOFOX"T" (Bruker AXS
Microanalysis GmbH, Berlin, Germany). The spectrometer specifications and operating conditions used are summarized in Table 2. This instrument is equipped with a W-target X-ray tube that allows TXRF analysis using K-lines of high atomic number elements such as $\mathrm{Cd}$. An additional advantage of this spectrometer compared to other existing systems is that it uses an air-cooled low-power X-ray tube and a Peltier cooled silicon drift detector and thus, no cooling media or gases are required.

The operating conditions for TXRF measurements were checked periodically to ensure the quality of the obtained results. Some tests were performed for this purpose following the manufacturer's recommendations: (i) fine adjustment of the spectroscopic amplification (gain correction) was performed by means of the measurement of a Rb-standard on a quartz glass carrier at the level of $1 \mu \mathrm{g}$; (ii) the spectroscopic resolution (FWHM) was monitored analysing a Mn-standard on a quartz glass reflector with a cumulative count rate of $10000 \mathrm{cps} \pm 20 \%$; (iii) instrumental sensitivity was determined by the measurement of a $3 \mathrm{ng}$ Cd standard on a quartz reflector; and (iv) the accuracy of quantification was checked by the analysis of a multi-element standard with certified element concentrations (Merck VI standard).

Table 2 Instrumental parameters and measurement conditions

$\begin{array}{ll}\text { S2 PICOFOX TXRF benchtop spectrometer } \\ \text { X-Ray tube } & \text { W } \\ \text { Rating } & 50 \mathrm{kV}, 1 \mathrm{~mA} \text { (maximum power } 50 \mathrm{~W} \text { ) } \\ \text { Optics } & \text { Multilayer Ni/C, } 17.5 \mathrm{keV}, 80 \% \mathrm{reflectivity} \\ \text { Detector } & \text { Si drift detector, } 10 \mathrm{~mm}^{2},<160 \mathrm{eV} \\ & \text { resolution Mn-K } \alpha \\ \text { Working environment } & \text { Air } \\ \text { Sample station } & \text { Cassette changer for } 25 \mathrm{samples} \\ \text { Size, weight } & 600 \times 300 \times 450 \mathrm{~mm}, 37 \mathrm{~kg}\end{array}$

Agilent 7500c ICP-MS spectrometer

RF power $1500 \mathrm{~W}$

Plasma gas flow rate $\quad 15 \mathrm{~L} \mathrm{~min}^{-1}$

Nebuliser gas flow rate $\quad 1.12 \mathrm{~L} \mathrm{~min}^{-1}$

Sampling cone $\quad \mathrm{Ni}, 1 \mathrm{~mm}$ aperture diameter

Skimmer cone $\quad \mathrm{Ni}, 0.4 \mathrm{~mm}$ aperture diameter

Integration time for each $0.1 \mathrm{~s}$

isotope

Readings per replicate 3

Signal measurement mode Three points per peak

Isotopes monitored $\quad{ }^{111} \mathrm{Cd},{ }^{103} \mathrm{Rh}$ (as internal standard)

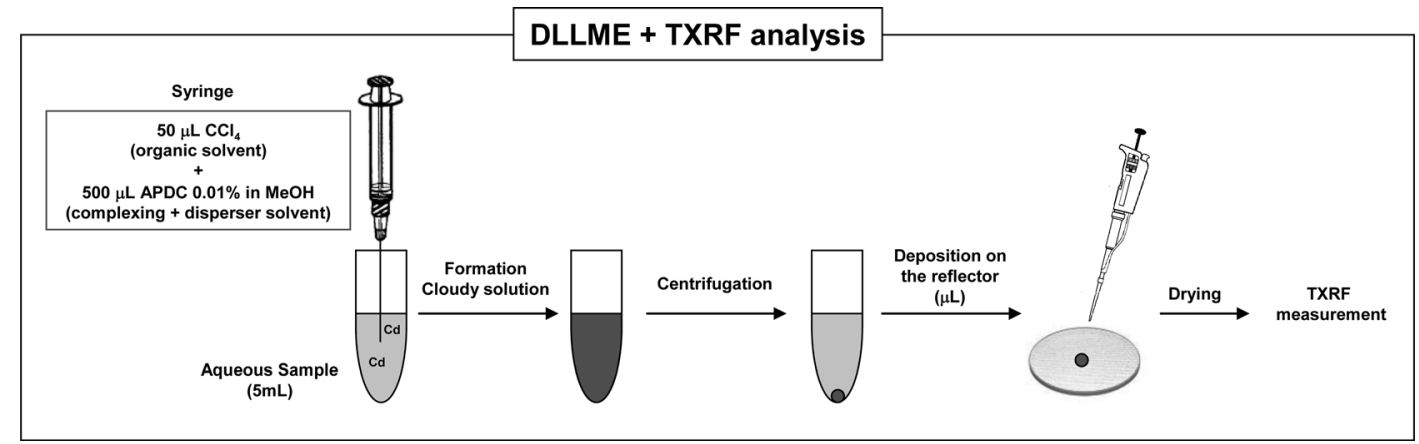

Fig. 1 Schematic setup for a dispersive liquid-liquid microextraction procedure combined with TXRF analysis. 
The evaluation of TXRF spectra and calculation of the analyte net peak area were performed using the software (Spectra Plus 5.3, Bruker AXS Microanalysis GmbH, Berlin, Germany) supplied with the equipment. ${ }^{22}$ For quantification using TXRF spectra, the software applies a deconvolution routine which uses measured mono-element profiles for the evaluation of peak areas.

In order to evaluate the extraction efficiency of the preconcentration procedure used, the Cd content in liquid samples (before and after the LPME procedure) was determined by a quadrupole-based ICP-MS system (Agilent 7500c, Agilent Technologies, Tokyo, Japan) equipped with an octapole collision cell. As a means of increasing the accuracy of Cd determination at low concentration levels, appropriate amounts of $\mathrm{Rh}$ internal reference solution were added to the aqueous samples of concern. The instrumental parameters employed are summarized in Table 2.

\section{Results and discussion}

\subsection{Selection of experimental conditions for $\mathrm{Cd}$ extraction by the DLLME procedure}

In order to obtain a high cadmium preconcentration rate, the effect of different parameters affecting cadmium extraction such as the type of organic solvent, $\mathrm{pH}$, concentration of chelating agent, aqueous sample volume and disperser agent type were carefully evaluated. One variable at a time optimization was used to obtain the most favorable conditions for the DLLME procedure. In this study, APDC was selected as the complexing agent because of the low solubility of the resulting metal chelates.
Firstly, the effect of six different organic solvents commonly used in conventional liquid-liquid extraction procedures (hexylbenzene, undecane, carbon tetrachloride, chloroform, dihexyl ether and decahydronaphthalene) was evaluated for CdPDC complex extraction. In all cases, cadmium concentration was $3 \mu \mathrm{g} \mathrm{L}^{-1}$, the volume of the aqueous sample was $5 \mathrm{~mL}$ and the volume of the organic solvent was $50 \mu \mathrm{L}$. The solubility of the extraction solvents in water differed and only by using carbon tetrachloride and chloroform were we able to obtain a final sedimented phase volume higher than $20 \mu \mathrm{L}$ (required volume for subsequent TXRF analysis). Carbon tetrachloride also provided higher cadmium extraction efficiency and therefore it was selected as the organic phase in the DLLME system.

The effect of $\mathrm{pH}$ on the formation and extraction of the CdPDC complex was also studied within the range of 1.4 to 8.2. As is shown in Fig. 2A, the analytical signal for cadmium was relatively constant in the $\mathrm{pH}$ range of 1-5 and diminishes at higher pHs. A pH value of 3.0 was selected for further studies.

Different concentrations of APDC were also tested to evaluate its influence on Cd extraction (see Fig. 2B). The results indicated that the cadmium analytical signal increased with increasing APDC concentrations from $0.001 \%$ to $0.005 \%$ as a result of the high extraction efficiency of the CdPDC complex to carbon tetrachloride microdrop. The extraction efficiency remained constant from $0.005 \%$ to $0.01 \%$ and decreased when using higher APDC concentrations. Taking into account the likely competitive complexation of APDC with other metal ions in the real samples, an APDC concentration of $0.01 \%$ was chosen for the following experiments.

Another parameter that can significantly affect the global sensitivity of the methodology is the volume of the aqueous sample used for preconcentration. To evaluate this effect,
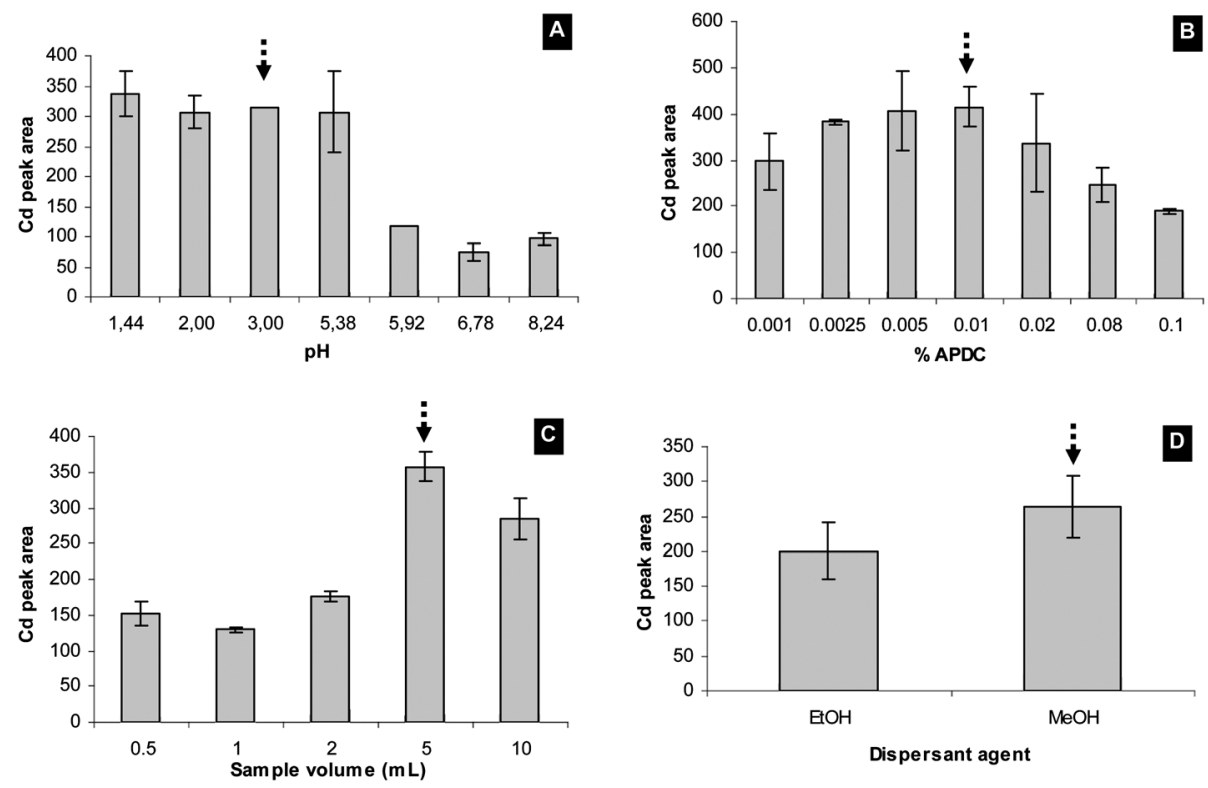

Fig. 2 Optimization of the DLLME procedure: (A) effect of $\mathrm{pH}\left([\mathrm{Cd}]=3 \mu \mathrm{g} \mathrm{L}^{-1}\right.$, [APDC] $=0.01 \%, 5 \mathrm{~mL}$ aqueous sample, $\left.50 \mu \mathrm{L} C \mathrm{CC} \mathrm{H}_{4}, 500 \mu \mathrm{L} \mathrm{MeOH}\right),(\mathrm{B})$ effect of $\mathrm{APDC}$ amount, $\left([\mathrm{Cd}]=3 \mu \mathrm{g} \mathrm{L}^{-1}, \mathrm{pH}=3.0,5 \mathrm{~mL}\right.$ aqueous sample, $\left.50 \mu \mathrm{L} \mathrm{CCl}, 500 \mu \mathrm{L} \mathrm{MeOH}\right),(\mathrm{C})$ effect of sample volume, $\left([\mathrm{Cd}]=3 \mu \mathrm{g} \mathrm{L}^{-1},[\mathrm{APDC}]=0.01 \%, \mathrm{pH}=3.0,50 \mu \mathrm{L}\right.$ $\left.\mathrm{CCl}_{4}, 500 \mu \mathrm{L} \mathrm{MeOH}\right)$, and (D) effect of disperser solvent $\left([\mathrm{Cd}]=3 \mu \mathrm{g} \mathrm{L}{ }^{-1},[\mathrm{APDC}]=0.01 \%, \mathrm{pH}=3.0,[\mathrm{APDC}]=0.01 \%, 5 \mathrm{~mL} \text { aqueous sample, } 50 \mu \mathrm{L} \mathrm{CCl}\right)_{4}$. Error bars represent the standard deviation of two replicates. 

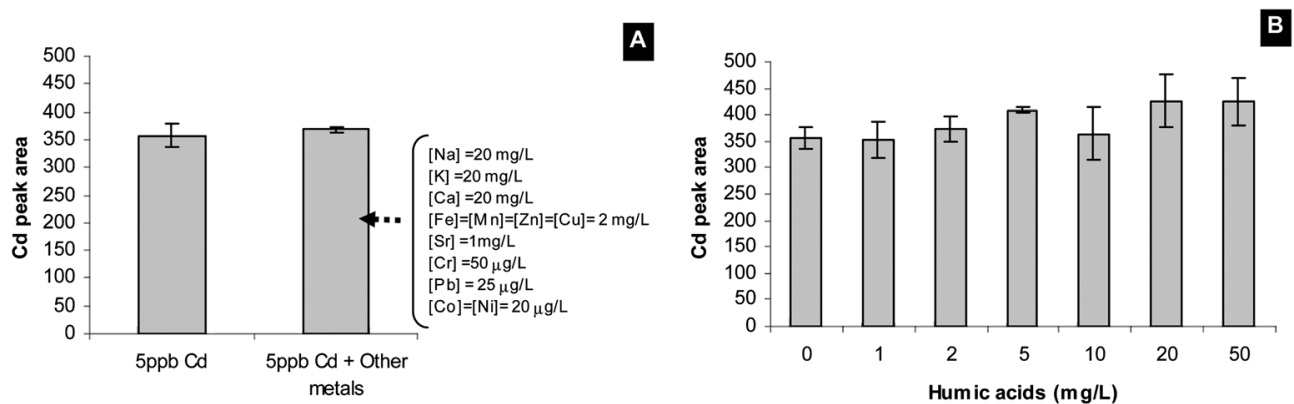

Fig. 3 Effect of humic acids (A) and co-existing ions (B) on cadmium determination by DLLME ([Cd] $=3 \mu g \mathrm{~L}^{-1}$, experimental conditions, Fig. 2). Error bars represent the standard deviation of two replicates.

increasing sample volumes of the aqueous phase (from 0.5 to $10 \mathrm{~mL}$ ) were tested. In all cases, a constant volume of carbon tetrachloride of $50 \mu \mathrm{L}$ was used. As shown in Fig. $2 \mathrm{C}$, the cadmium analytical signal was nearly constant in the range of 0.5 to $2 \mathrm{~mL}$ and increases considerably when using higher sample volumes. According to the obtained results, an aqueous sample volume of $5 \mathrm{~mL}$ (corresponding to an aqueous to organic volume ratio of 100) was selected.

Finally, the use of two different disperser solvents (methanol and ethanol) was also evaluated (see Fig. 2D). The main criterion for selection of the disperser solvent was its miscibility in both the extraction solvent and aqueous phase. To study the influence of methanol and ethanol on Cd extraction, two experiments were performed using $500 \mu \mathrm{L}$ of each disperser solvent containing $50 \mu \mathrm{L}$ of carbon tetrachloride (extraction solvent) and $0.01 \%$ of APDC (complexing agent). The solubility of APDC in both solvents was adequate but the cadmium signal was significantly higher when using methanol to perform the microextraction procedure and thus it was selected as a disperser agent.

In view of the presence of potential interference ions and organic load in most environmental water samples, it was also considered appropriate to study the influence of such compounds in the extraction of cadmium using the best experimental conditions described above. For that, synthetic water samples containing $3 \mu \mathrm{g} \mathrm{L}^{-1}$ of cadmium with and without different amounts of other coexisting ions and humic acids usually present in natural water samples were analyzed (see Fig. 3 for details). In all cases, the presence of other ions and humic acids did not affect the extraction and determination of cadmium at the working concentration levels.

\subsection{Optimization of the sample deposition step and analytical conditions for TXRF measurements}

The aim of the sample preparation process in TXRF is to obtain the target sample as a thin layer $(<100 \mu \mathrm{m})$ on a carrier with high reflectivity sample support. Therefore, the choice of adequate sample deposition volume is of crucial importance in order to obtain a thin layer and to ensure the conditions of total reflection. Moreover, the diameter of the sample spot on the sample carrier has to be within the beam size to ensure the complete exposition of the drop to the X-ray beam. For that, only a few microliters of solution are usually employed. In Fig. 4A, the effect of sample deposition volume on the Cd peak area obtained for the analysis of a preconcentrated standard solution containing $3 \mu \mathrm{g} \mathrm{L}^{-1}$ of Cd is shown. As can be seen, no statistically significant differences in analyte response were obtained when depositing 5 or $10 \mu \mathrm{L}$ of sample on the reflector. There were also no differences between the results obtained using a single deposition of $10 \mu \mathrm{L}$ of the sample and those obtained when depositing $5 \mu \mathrm{L}$ sequentially in the same location with time allowed for droplet drying between successive depositions. However, a significant increase on the Cd peak area was found when $20 \mu \mathrm{L}$ of sample was deposited on the quartz disc. In view of the obtained results, a volume of $20 \mu \mathrm{L}$ was established for further experiments since using this volume the sample was provided as a centered-thin film on the reflector and, moreover, a higher absolute element
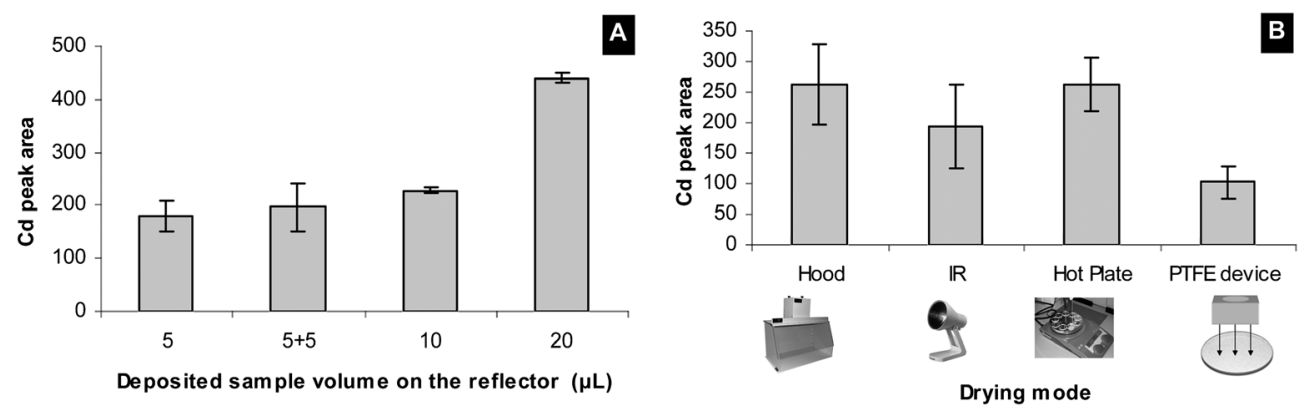

Fig. 4 Effect of sample volume deposited on the reflector and drying mode on cadmium determination ([Cd] $=3 \mu g \mathrm{~L}^{-1}$, experimental conditions, Fig. 2). Error bars represent the standard deviation of two replicates. 
sensitivity was obtained compared to that achieved when using 5 $\mu \mathrm{L}$ or $10 \mu \mathrm{L}$ of sample.

After the deposition procedure on the reflector the microdroplet must be properly dried to perform the TXRF analysis. Therefore, another parameter that can significantly affect the final analytical TXRF results is the drying method used. Usually, drying of aqueous samples deposited on quartz reflectors is easily performed by heating using an IR-lamp. ${ }^{23}$ However, in this application the sample deposited on the reflector is not an aqueous sample but consists of $20 \mu \mathrm{L}$ of carbon tetrachloride and the proper deposition/drying of the organic drop on the quartz reflector surface is not easy. For that, different deposition/drying modes were tested in order to ensure the production of a centered-thin film on the reflector when analyzing a preconcentrated standard solution containing $3 \mu \mathrm{g} \mathrm{L} \mathrm{L}^{-1}$ of Cd: (i) drying under a laminar flow hood (room temperature) after deposition; (ii) drying under an IR-lamp after deposition; (iii) deposition of the drop on a preheated quartz reflector using a hot plate set at $\sim 80{ }^{\circ} \mathrm{C}$; and (iv) depositing the drop using a home-made designed funnel-shaped device of PTFE (see Fig. 4B) and drying under the laminar flow hood. In the latter case, the device should allow evaporation of the sample onto a geometric spot in the center of the quartz reflector. However, it was observed that when using the PTFE device to deposit the sample, a smaller Cd-peak area was obtained surely due to the loss of part of the deposited residue on PTFE walls (Fig. 4B). This procedure was finally discarded because of this undesired effect. The use of an IR-lamp for drying was also excluded due to the unwanted movement of the organic drop to the quartz reflector's edges during the heating/drying step. Taking into account the obtained results, the best deposition/drying mode was found to be the deposition of the drop on a preheated quartz reflector using a hot plate set at $\sim 80^{\circ} \mathrm{C}$. Using this procedure, the Cd signal was similar to that obtained when drying the organic drop on the reflector at room temperature under a laminar flow hood but the time required was significantly reduced. It is important to remark that the use of volatile halogen-containing organic solvents (i.e., carbon tetrachloride) are not really suitable to be injected into the graphite furnace of ETAAS $^{24}$ but are adequate to be analyzed by TXRF if an appropriate deposition/drying mode is used.

Operating conditions for TXRF measurements were also evaluated to obtain the best instrumental sensitivity for $\mathrm{Cd}$ determination. Firstly, and taking into account the type of matrix and the concentration of the studied element, the rate of $\mathrm{kV} \mathrm{mA}^{-1}$ of the X-ray tube was selected to work under conditions of maximum efficiency of excitation $(50 \mathrm{kV}, 1 \mathrm{~mA}$, max. power $50 \mathrm{~W}$ ). A measuring time of $2000 \mathrm{~s}$ was selected as a tradeoff between an acceptable instrumental sensitivity, repeatability of measurements and total analysis time.

\subsection{Analytical figures of merit for the DLLME-TXRF system}

First of all, a study was conducted to evaluate the benefits of the proposed preconcentration methodology for Cd determination in aqueous solutions by using TXRF. Aliquots of $20 \mu \mathrm{L}$ of an aqueous standard solution at the level of $100 \mu \mathrm{g} \mathrm{L} \mathrm{L}^{-1}$ of $\mathrm{Cd}$ and $20 \mu \mathrm{L}$ of a preconcentrated standard solution containing $3 \mu \mathrm{g}$ $\mathrm{L}^{-1}$ of Cd were analyzed with the aforementioned TXRF spectrometer. In Fig. 5, spectra obtained for the analysis of both samples are displayed. It is clear that the proposed DLLME preconcentration method offers huge benefits in terms of sensitivity compared to analysis of aqueous samples without preconcentration. If the parameters for these spectra (net intensity and background) are used to estimate the detection limits according to the $3 \sigma$ approach, ${ }^{23}$ values of approximately

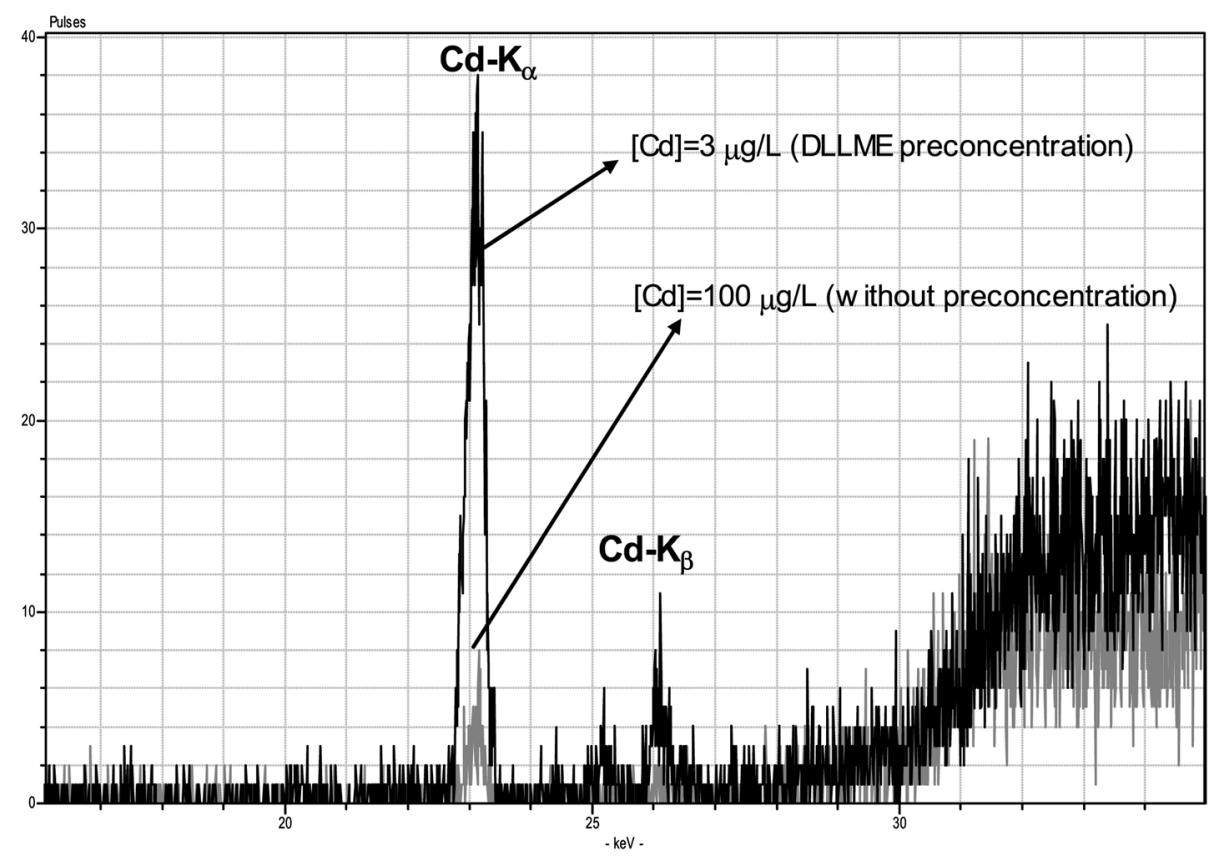

Fig. 5 Comparison between TXRF spectra obtained for the direct analysis of an aqueous standard containing $100 \mu \mathrm{g} \mathrm{L}-1$ of $\mathrm{Cd}$ (grey straight line) and of an aqueous standard containing $3 \mu \mathrm{g} \mathrm{L}^{-1}$ of Cd after the DLLME procedure (black straight line). In both cases: deposited sample volume: $20 \mu \mathrm{L}$ and measuring time: $2000 \mathrm{~s}$. 
$5 \mu \mathrm{g} \mathrm{\textrm {L } ^ { - 1 }}$ of $\mathrm{Cd}$ and $0.04 \mu \mathrm{g} \mathrm{L}^{-1}$ of $\mathrm{Cd}$ are obtained for the analysis of $\mathrm{Cd}$ in aqueous samples without and with preconcentration, respectively. The limit of detection obtained combining DLLME and TXRF analysis is more than 100 times lower than the maximum $\mathrm{Cd}$ content permissible in drinking waters, as stated in the introduction, indicating that the proposed method can be suitable for such determination.

Although the minimum $\mathrm{Cd}$ concentration that can be detected in this work is rather higher than those associated with other popular spectrometric techniques such as ETAAS and ICPMS in combination with LPME (see Table 1), the low operating and maintenance costs of the TXRF benchtop system (cooling media and gas consumption are not needed) make this analytical technique an interesting and complementary analytical tool combined with LPME strategies for the determination of Cd in different environmental water samples.

Taking into account that for TXRF measurements samples are prepared as thin layers no matrix effects such as absorption and enhancement, common to WDXRF and EDXRF spectrometry, occur. ${ }^{23}$ Therefore, it can be assumed that the intensities are proportional to the mass fractions of the elements of interest. For that reason, internal standardization is one of the most commonly used strategies for quantification purposes in TXRF analysis. It is based on the addition of a defined amount of a liquid mono-element standard (internal standard) to the target sample. Then the concentration of the respective elements in the sample are calculated, taking into account the signal and concentration of the internal standard in the sample and a single set of relative sensitivities usually linked to the instrument software. However, in this particular application internal standardization was not suitable for quantification purposes since the extraction efficiency of the LPME system, calculated from the difference between the cadmium concentration at the beginning of the experiment and the concentration after the LPME procedure determined by ICP-MS, was lower than $100 \%$ (a constant value close to $80 \%$ was achieved), independent of the initial metal concentration $\left(0.5 \mu \mathrm{g} \mathrm{\textrm {L } ^ { - 1 }}\right.$ and $5.0 \mu \mathrm{g}$ $\mathrm{L}^{-1}$ of $\mathrm{Cd}$ ). Therefore, for calibration purposes, external calibration had to be employed. The entire preconcentration and detection procedure described above was applied to aqueous standard solutions containing Cd concentrations in the range of $0.2-50 \mu \mathrm{g} \mathrm{L}^{-1}$ and were taken through the whole concentration and detection procedure described above. Cadmium peak areas obtained under the selected operating conditions were plotted versus known concentrations of $\mathrm{Cd}$ in the liquids and a straight line was fitted to measured points by the least-squares method (confidence limit 95\%). Results showed that a nonlinear relationship between the Cd signal and analyte concentration exists for Cd concentrations in the aqueous phase above $10 \mu \mathrm{g} \mathrm{L}^{-1}$. The limited linear concentration range is in accordance with other methodologies using LPME systems as shown in Table 2. However, we can expand the linear concentration range of the developed methodology by increasing the volume of carbon tetrachloride used during the DLLME procedure (see Fig. 6 for details). According to Fig. 6 we can increase the linearity range from $10 \mu \mathrm{g} \mathrm{L}^{-1}$ to $50 \mu \mathrm{g} \mathrm{L}^{-1}$ if we increase the volume of organic solvent from $50 \mu \mathrm{L}$ to $200 \mu \mathrm{L}$. Therefore, we can modify the external calibration depending on the expected Cd concentration range in the target aqueous samples. However, it has to be noted that when increasing the volume of organic solvent the lower concentration range also increases (from $0.2 \mu \mathrm{g} \mathrm{L} \mathrm{L}^{-1}$ to $\left.1 \mu \mathrm{g} \mathrm{L}^{-1}\right)$. This fact could be of particular interest if ultratrace cadmium determination is required.

The global precision of the LPME-TXRF methodology was evaluated in terms of relative standard deviation (RSD) of six replicate analyses of preconcentrated standard solutions containing $3 \mu \mathrm{g} \mathrm{L}^{-1}$ of $\mathrm{Cd}$. The RSD calculated was $5.0 \%$, which is an acceptable value taking into account the manipulation of small volumes of solutions and reagents inherent to the use of LPME systems and also due to the deposition of few microliters of sample on the quartz reflectors for the later TXRF analysis. In addition to quantification purposes, in TXRF the use of an internal standard can reduce the inaccuracies due to sample deposition on the sample carrier. Therefore, the use of an internal standard (Mo) was tested in order to improve the precision related to the sample deposition procedure. An adequate volume of a Mo stock solution of $1000 \mu \mathrm{g} \mathrm{g}^{-1}$ in an oil matrix was added to carbon tetrachloride to obtain a final Mo concentration of $10 \mathrm{mg} \mathrm{kg}^{-1}$. Then, $50 \mu \mathrm{L}$ of this organic solution was used as the extractant solvent in the DLLME procedure. RSD values calculated from the relative Cd signal (Cd signal/Mo signal) obtained in the analysis of six replicate analyses of
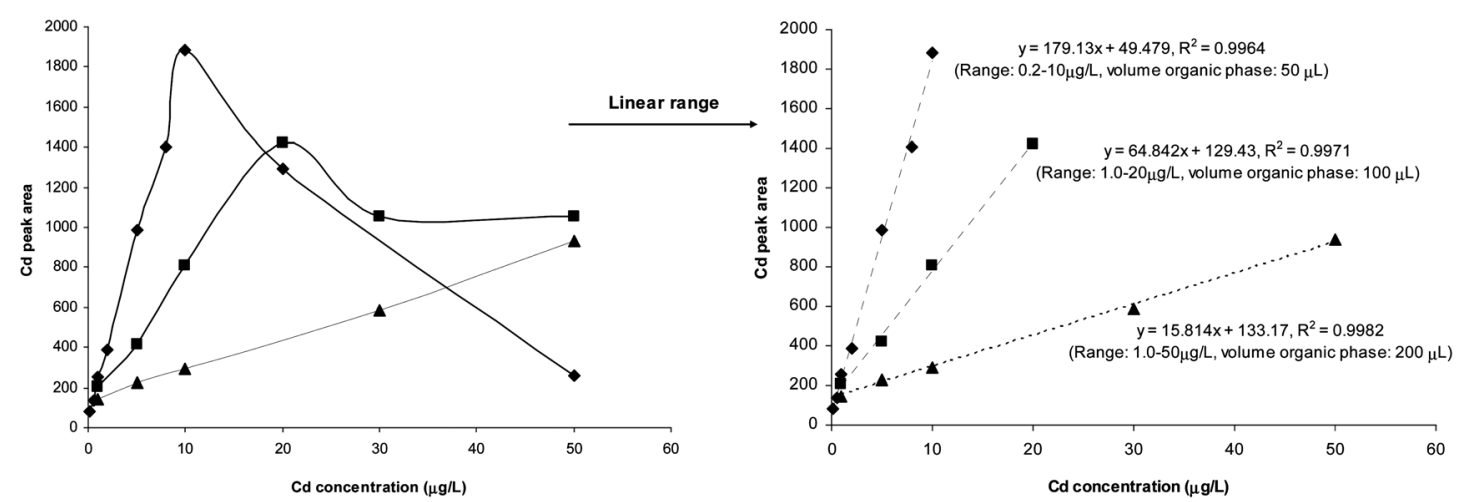

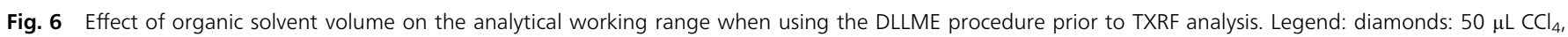
squares: $100 \mu \mathrm{LCCl}_{4}$, triangles: $200 \mu \mathrm{LCCl}_{4}$. 
Table 3 Analytical results (mean $\pm S D, n=2$ ) for cadmium in water samples ${ }^{a}$

\begin{tabular}{llc}
\hline Sample & Added $\left(\mu \mathrm{g} \mathrm{L}^{-1}\right)$ & Found $\left(\mu \mathrm{g} \mathrm{L}^{-1}\right)$ \\
\hline Estuarine water & 0 & n.d. \\
& 1 & $1.2 \pm 0.2$ \\
River water & 5 & $5 \pm 1$ \\
& 0 & n.d. \\
Sea water & 1 & $0.9 \pm 0.1$ \\
& 5 & $5 \pm 1$ \\
& 0 & n.d. \\
${ }^{a}$ n.d.: not detected. & 1 & $1.06 \pm 0.06$ \\
& 5 & $5 \pm 1$ \\
\hline
\end{tabular}

preconcentrated standard solutions containing $3 \mu \mathrm{g} \mathrm{\textrm {L } ^ { - 1 }}$ of Cd were considered. It was found that the RSD value calculated using Mo as an internal standard was 15.6\%. Therefore, internal standardization was discarded for further experiments since the precision related to sample deposition was not improved. This fact can be explained by the loss of part of the internal standard from the organic phase to the aqueous phase during the DLLME procedure.

\subsection{Application of the developed methodology to the determination of $\mathrm{Cd}$ in environmental water samples}

To test the real capability of the combination of DLLME and TXRF spectrometry for the intended purpose, the developed procedure was applied to the determination of $\mathrm{Cd}$ in different types of environmental waters including estuarine, river and sea water samples. As shown in Table 3, Cd concentration was below the detection limit for all the analyzed samples. However, in order to validate the methodology for the different types of environmental water samples, the target samples were spiked with 1 and $5 \mu \mathrm{g} \mathrm{L}^{-1}$ of $\mathrm{Cd}$. The recovery of the spiked samples (Table 3) was, in most cases, in the range of $90-106 \%$, which demonstrates the suitability of the TXRF methodology for monitoring $\mathrm{Cd}$ at trace levels in environmental water samples including sea water samples. This fact is of significance taking into account the quantification problems when analyzing high salt content solutions by TXRF. ${ }^{23}$

\section{Conclusions}

The results of the present investigation show that DLLME combined with TXRF spectrometry is a powerful methodology for the determination of low levels of cadmium in aqueous samples in a simple, non-time consuming and low-cost way. With the described procedure, the LoDs for Cd are improved by more than two orders of magnitude compared with the direct analysis of Cd by TXRF. This fact is particularly interesting when using benchtop TXRF systems that offer extreme simplicity of operation in a low-cost compact design (no cooling media or gas consumption are required for operation) but they also present limited sensitivity compared with high-scale instrumentation. The presented methodology has been successfully applied to the quantification of $\mathrm{Cd}$ in the low $\mu \mathrm{g} \mathrm{L}^{-1}$ range in different types of spiked environmental water samples, including sea water. Moreover, the accuracy and precision of the results attained are satisfactory for the intended purposes.

\section{Acknowledgements}

This work was supported by the Spanish National Research Progam (Project ref. CGL2010-22168-C03-01). A. Manzano is acknowledged for her support in the laboratory work.

\section{References}

1 World Health Organization (WHO), Guidelines for Drinking Water Quality, Health Criteria and Other Supporting Information, World Health Organization, Geneva, 2nd edn, 1998, vol. 2.

2 Environmental Protection Agency, EPA, Second edition of the drinking water standards and health advisories, EPA 822-R-02-38, Washington DC, 2002, http://www.epa.gov/ waterscience/drinking/standards.html.

3 E. Marguí, J. C. Tapias, A. Casas, M. Hidalgo and I. Queralt, Chemosphere, 2010, 80, 263-270.

4 N. Szoboszlai, Z. Polgári, V. G. Mihucz and G. Záray, Anal. Chim. Acta, 2009, 633, 1-18.

5 N. V. Alov, Inorg. Mater., 2011, 47, 1487-1499.

6 C. Streli, Appl. Spectrosc. Rev., 2006, 41, 473-489.

7 A. Prange and H. Schwenke, Adv. X-Ray Anal., 1989, 32, 211-218.

8 S. Dadfarnia and A. M. H. Shabani, Anal. Chim. Acta, 2010, 658, 107-119.

9 A. N. Anthemidies and I. S. I. Adam, Anal. Chim. Acta, 2009, 632, 216-220.

10 S. Nazari, Microchem. J., 2008, 90, 107-112.

11 H. Jiang and B. Hu, Microchim. Acta, 2008, 161, 101-107.

12 Z. Fan and W. Zhou, Spectrochim. Acta, Part B, 2006, 61, 870874.

13 L. Li, B. Hu, L. Xia and Z. Jiang, Talanta, 2010, 70, 468-473. 14 S. Dadfarnia, A. M. H. Shabani and E. Kamranzadeh, Talanta, 2009, 79, 1061-1065.

15 R. E. Rivas, I. López-García and M. Hernández-Córdoba, Anal. Methods, 2010, 2, 225-230.

16 J.-F. Peng, R. Liu, J.-F. Lu, B. He, X.-L. Hu and G.-B. Jiang, Spectrochim. Acta, Part B, 2007, 62, 499-503.

17 L. Xia, Y. Wu and B. Hu, J. Mass Spectrom., 2007, 42, 803-810.

18 E. Z. Jahromi, A. Bidari, Y. Assadi, M. R. M. Hosseini and M. R. Jamali, Anal. Chim. Acta, 2007, 585, 305-311.

19 R. E. Rivas, I. López-García and M. Hernández-Córdoba, Microchim. Acta, 2009, 166, 355-361.

20 S. Li, S. Cai, W. Hu, H. Chen and H. Liu, Spectrochim. Acta, Part B, 2009, 64, 666-671.

21 E. Marguí, M. Cejudo, I. Queralt, M. Hidalgo, unpublished work.

22 S2 PICOFOX ${ }^{\mathrm{TM}}$ User Manual, Bruker advanced X-ray solutions, Bruker AXS Microanalysis GmH, Berlin, Germany.

23 R. Klockenkämper in, Total Reflection X-ray Fluorescence Analysis, ed. J. D. Winefordner, John Wiley \& Sons, New York, 1997.

24 F. Pena-Pereira, I. Lavilla and C. Bendicho, Spectrochim. Acta, Part B, 2009, 64, 329-333. 